\title{
A fuzzy MCDA framework for safety assessment in the remediation of a uranium mill tailings site in Ukraine
}

\author{
A. Jiménez ${ }^{1}$, M.C. Martín ${ }^{1}$ A. Mateos ${ }^{1}$, D. Pérez-Sánchez ${ }^{2}$, A. Dvorzhak ${ }^{2}$ \\ 1 Decision Analysis and Statistics Group, Departamento de Inteligencia Artificial, Universidad \\ Politécnica de Madrid (UPM), Spain \\ 2 Departamento de Medio Ambiente, Centro de Investigaciones Energéticas, Medioambientales y \\ Tecnológicas (CIEMAT), Spain
}

\begin{abstract}
The Pridneprovsky Chemical Plant was one of the largest uranium processing enterprises in the former USSR, producing a huge amount of uranium residues. The Zapadnoe tailings site contains most of these residues. We propose a theoretical framework based on multicriteria decision analysis and fuzzy logic to analyze different remediation alternatives for the Zapadnoe tailings, which simultaneously accounts for potentially conflicting economic, social and environmental objectives. We build an objective hierarchy that includes all the relevant aspects. Fuzzy rather than precise values are proposed for use to evaluate remediation alternatives against the different criteria and to quantify preferences, such as the weights representing the relative importance of criteria identified in the objective hierarchy. Finally, we suggest that remediation alternatives should be evaluated by means of a fuzzy additive multi-attribute utility function and ranked on the basis of the respective trapezoidal fuzzy number representing their overall utility.
\end{abstract}

\section{INTRODUCTION}

The Zapadnoe uranium mill tailings site (Zapadnoe tailings) is situated in the south-western part of the main industrial site of the former Pridneprovsky Chemical Plant (PChP), located at Dneprodzerzhinsk (Ukraine). The tailings site operated from 1949 until 1954. The total volume of waste was $3.510^{5} \mathrm{~m}^{3}$ and the total activity was $1.810^{14} \mathrm{~Bq}$ (Bugay et al., 2012).

Uranium mill tailings, disposed of using the hydraulic discharge method, accounted for most of the wastes. The tailings site was covered in 2000 by an engineered multi-layer soil cover. As a result, the wastes are covered by a layer of non-radioactive backfill, composed of construction and industrial wastes, sand, clayey loam soils, clinker, rubbish etc. with a total thickness of 0.2 to $2.8 \mathrm{~m}$. The southern part of the tailings have been covered by a 0.3 to $1.0 \mathrm{~m}$ thick layer of crushed stone and asphalt layer. The slopes of the tailings pile are covered by layers of clay loam and organic soil, with a combined thickness of $0.5-1.0 \mathrm{~m}$.

The tailings are situated on the slope of a sequence of the terraces of the Dnepr River. The ground generally slopes from south to north. The tailings themselves are located within the second terrace. The first (lower) terrace is situated to the north of the tailings. The third and fourth (higher) terraces are situated to the south of the waste site. The tailings site was surrounding by dikes that were not surfaced with protective impermeable screens and are currently buried below the layers of backfilled soil. The surface of the tailing pile is equipped with a system for collecting runoff rainwater. This water runs into Konoplyanka River.

There are two aquifers at the Zapadnoe tailings site. The technogenic aquifer is a perched water horizon that is recharged by infiltration of atmospheric precipitation through the waste cover. The water from this aquifer infiltrates further down to the underlying aquifer in the alluvial deposits. The regional aquifer in the alluvial deposits is composed of alluvial sands, sandy loam and clay loam deposits. Loess deposits overlie and the upper part of the fissured crystal- 
line basement rocks underlies the alluvial deposits. The groundwater in the alluvial aquifer flows north towards the Konoplyanka and the Dnieper.

A series of rainfall events led to the erosion of the surface and slopes of the protective dikes from 2002 to 2004 . Remedial works were carried out in 2005. These works included backfilling the eroded areas with clayey soil, and enforcing the slopes by a geotechnical polymer net material. The eroded surfaces were covered by an organic soil layer and planted with grasses. The surface run-off drainage system was also repaired.

The tailings site is surrounded by other industrial sites and technological communications lines that employ 2500 people. The surface of the tailings site is equipped with warning signs prohibiting the entry of unauthorized personnel, but the site is not fenced.

There are currently two main sources of data regarding the physical, chemical and radioactive characteristics of wastes disposed the Zapadnoe tailings site. The first characterization studies were carried out in 2000 (STC-USR \& DIIT, 2000). Six characterization boreholes were drilled and the core material was subject to various lithological, chemical and radiometric analyses. The second characterization was carried out in 2009 as a part of the National PChP Remediation Program (UHMI, 2009). Information about radiation exposures due to contamination in soil, water and air was collected for various radionuclides. Water samples were also analyzed to obtain information on contamination by chemically toxic materials.

Discrepancies between the results of inventory studies carried out in 2000 and 2009 have been identified. In particular, the 2009 studies suggest that uranium and radium concentrations in the wastes are about a factor of two higher than previously estimated. The estimated mean thorium-230 activity increased by a factor of about 3, and discrepancies were also observed for lead-210.

More recently, the context for a safety assessment of the Zapadnoe tailings site has been described in Bugay et al. (2012). The safety assessment was carried out by Ecomonitor and GeoEco-Consulting following the steps set out in the ENSURE II project (funded by the Swedish International Development Agency, SIDA, to provide assistance to Ukraine in the remediation of uranium-contaminated territories and facilities at the Dnieprodzerchynsk industrial site)

Bugay et al. (2012) includes information on the operational history of the tailings site, on its engineering features, as well as on the chemical, physical and radioactive characteristics of the waste materials in the tailings. Environmental conditions (such as the geology, geomorphology and hydrogeological setting) and climate are also described.

Safety assessment can be considered as the starting point for an analysis of remediation alternatives. It would be equivalent to the no action alternative. The selection of a preferred remediation alternative is a complex decision-making problem, which has to take into account factors other than the radiological and chemical toxicity impacts of the wastes. For example, the direct costs of the application and maintenance of remediation alternatives (manpower, consumables, equipment needed for application, management), the job creation effects and other indirect costs or benefits should be considered as economic criteria. Social impacts, as well as direct impacts on human health and safety, should also be considered. These impacts include community satisfaction, and the impact of remediation on the social characteristics of the neighborhood.

\section{A FUZZY MCDA FRAMEWORK}

The goal of multi-criteria decision analysis (MCDA) is to structure and simplify the task of making hard decisions to the extent that as well and as easily as the nature of the decision permits (Belton, 1990). MCDA works on the assumption that the appeal of an alternative depends on the likelihood of the possible consequences of the alternative, and the preferences concerning the possible consequences.

What makes MCDA unique is the way in which these factors are quantified and formally incorporated into the problem analysis. Existing information, collected data, models and professional judgments are used to quantify the likelihoods of ranges of consequences, whereas utility theory is used to quantify preferences.

The usual or traditional approach to MCDA calls for single or precise values for the different model inputs, i.e., for the weights as well as for the performances of the alternatives in 
terms of the identified criteria. However, we adopt a less demanding approach for the decisionmaker (DM), who is able to provide fuzzy numbers instead of single values.

Fuzzy logic (FL) introduced by Zadeh (1965) is a mathematical modeling tool using vague or imprecise measurements. In FL, a linguistic scale is usually built to characterize model inputs (Dursun, 2007). Each linguistic term is associated with a triangular or trapezoidal fuzzy number (see Table 1 and Figure 1), and fuzzy arithmetic is used to compute model outputs.

Table 1. A fuzzy linguistic scale

\begin{tabular}{lc}
\hline Term & Trapezoidal fuzzy numbers \\
\hline Very Low & $(0,0,0.1,0.2)$ \\
Low & $(0.1,0.2,0.2,0.3)$ \\
Fairly Low & $(0.2,0.3,0.4,0.5)$ \\
Medium & $(0.4,0.5,0.5,0.6)$ \\
Fairly High & $(0.5,0.6,0.7,0.8)$ \\
High & $(0.7,0.8,0.8,0.9)$ \\
Very High & $(0.8,0.9,1,1)$ \\
\hline
\end{tabular}

Figure 1. A fuzzy linguistic scale.

As shown in Figure 1, we consider the set of trapezoidal fuzzy numbers with support on $[0,1], T F[0,1]$, i.e. $A=\left(a_{1}, a_{2}, a_{3}, a_{4} ; w_{\widetilde{A}}\right)$, with $0 \leq a_{1} \leq a_{2} \leq a_{3} \leq a_{4} \leq 1 ; 0 \leq w_{\widetilde{A}} \leq 1$ together with a membership function $\left(\mu_{\tilde{A}}: \Re \rightarrow\left[0, w_{\tilde{A}}\right]\right)$ :

$$
\mu_{\widetilde{A}}=\left\{\begin{array}{cc}
0 & \text { if } x<a_{1} \\
\frac{w_{\tilde{A}}\left(x-a_{1}\right)}{a_{2}-a_{1}} & \text { if } a_{1}<x<a_{2} \\
w_{\widetilde{A}} & \text { if } a_{2}<x<a_{3}, \\
\frac{w_{\tilde{A}}\left(x-a_{4}\right)}{a_{3}-a_{4}} & \text { if } a_{3}<x<a_{4} \\
0 & \text { if } a_{4}<x
\end{array}\right.
$$

indicating the degree of membership of any value $x \in \mathfrak{R}$ to the fuzzy number $\tilde{A}$.

We use the arithmetic proposed in (Xu et al., 2010) in $T F[0,1]$ for computations. Thus, if $\widetilde{A}_{1}=\left(a_{1}, b_{1}, c_{1}, d_{1} ; w_{\widetilde{A}_{1}}\right)$ and $\tilde{A}_{2}=\left(a_{2}, b_{2}, c_{2}, d_{2} ; w_{\widetilde{A}_{2}}\right)$, then

$$
\begin{aligned}
& \text { - } \widetilde{A}_{1} \oplus \widetilde{A}_{2}=\left(a_{1}+a_{2}-a_{1} a_{2}, b_{1}+b_{2}-b_{1} b_{2}, c_{1}+c_{2}-c_{1} c_{2}, d_{1}+d_{2}-d_{1} d_{2} ; \min \left\{w_{\widetilde{A}_{1}}, w_{\widetilde{A}_{2}}\right\}\right), \\
& \text { - } \widetilde{A}_{1} \otimes \widetilde{A}_{2}=\left(a_{1} \square a_{2}, b_{1} \square b_{2}, c_{1} \square c_{2}, d_{1} \square d_{2} ; \min \left\{w_{\widetilde{A}_{1}}, w_{\widetilde{A}_{2}}\right\}\right) .
\end{aligned}
$$

The fuzzy number resulting from such a computation is usually translated into a linguistic term on the previously defined scale by means of a similarity function (Vicente et al., 2013).

Following the MCDA methodology, we build an objective hierarchy including all relevant criteria and then establish attributes for the bottom-level objectives of the hierarchy to indicate to what extent they are achieved.

The performance of each of the options in relation to each of the considered attributes has to be determined from the results of the safety assessment and other studies, and translated into a trapezoidal fuzzy number. Also, the relative importance of the attributes in the objective hierarchy has to be represented by means of trapezoidal fuzzy numbers. Finally, a fuzzified additive utility function can be used to derive a global utility value for each option, on the basis of which remediation alternatives can be ranked.

\subsection{Problem structuring}

To identify the criteria to be incorporated into the analysis, we consulted experts taking part in the ENSURE II project and reviewed the literature on applications of MCDA for evaluating remediation alternatives (e.g. Brinkhoff, 2011), and especially on applications to uranium mill tailings sites (e.g. Goldammer et al., 1999). 
On this basis, we built an objective hierarchy applicable to remediation options for the Zapadnoe tailings site (Figure 2). There are three main top-level criteria for the appropriate management of the Zapadnoe tailings site (overall objective): environmental impact, social impact and economic impact.

The environmental impact is caused by contaminants discharged into surface waters that can impair the functioning of aquatic biota and by infiltration through the tailings to the underlying aquifer, which has an impact on groundwater bodies. Both radioactive and toxic chemical contamination is taken into account and measured in terms radiation dose or degree of chemical exposure. The doses and exposures derived from the safety assessment are adopted as reference values for the no action alternative with respect to these values and remediation options are evaluated.

The social impact is split into four sub-objectives. Human health and safety refers both to radiological and toxicological impacts on humans. Radiological impacts take into account external irradiation, inhalation and ingestion (including both drinking water and diet), whereas toxicological impacts relate only to inhalation and ingestion. Again, doses and exposures derived from the safety assessment are adopted as reference values for the no action alternative and remediation options are evaluated in terms of differences from those values.

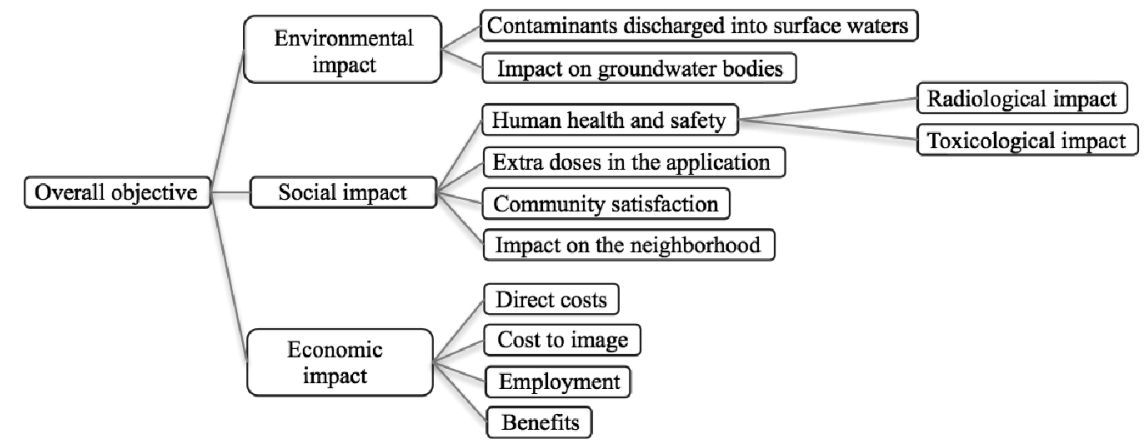

Figure 2. Objective hierarchy.

The Extra doses in the application of remediation alternatives objective refers to radiation doses and chemical exposures received as a consequence of the process of implementing a remediation alternative and relates both to workers and the general public.

Community satisfaction refers to how a remediation alternative is perceived by individuals belonging to a critical group living in the area, and impact on the neighborhood accounts for the impact on the local community as a whole, including dust, light, noise, odor and vibration during the remediation works and associated with traffic, including working-day and nighttime and weekend operations. A subjective scale is used in both cases, i.e. by directly selecting a term from the fuzzy linguistic scale in Table 1.

Under Economic impact, Direct costs refer to the costs of the implementation and maintenance of a remediation alternative (manpower, consumables, equipment needed for implementation, management requirements). This is a monetary attribute. Cost to image comprises indirect costs associated with a remediation alternative. It relates to public perceptions, e.g. a reluctance to purchase products from the area, even if uncontaminated, or a drop in tourism. Both the no action alternative and the various remediation options may have associated indirect costs. A subjective scale is used. Employment corresponds to job creation during and after the implementation of a remediation alternative. Short- and long-term jobs are taken into account, and the respective attribute is measured in person-months. Finally, Benefits refers to direct economic benefits associated with the implementation of a remediation alternative (e.g., sale of waste materials for reuse). It is measured in monetary units

Note that all the criteria apply when evaluating remediation alternatives, but some, such as the impact on the neighborhood, direct costs, employment or possible benefits are directly associated with the implementation of remediation alternatives and are not considered in the no 
action alternative. Imprecise estimates are allowed for by means of interval values in the fuzzy logic.

\subsection{Elicitation of expert preferences}

The GMAA decision support system provides two procedures for assessing component utilities (Jiménez et al., 2006). They represent the expert's preferences concerning the possible alternative performances: directly constructing a piecewise linear utility function by providing the best and the worst attribute values and up to three intermediate values with their respective imprecise utilities; or on the basis of indifference judgments between lotteries and sure amounts. In both cases, the system admits value intervals to be specified as responses to the probability questions the DM is asked, which leads to classes of utility functions (see Figure 3).

As interval values represent imprecise performances, a fuzzy component utility will be derived from a particular interval through the class of utility functions (see Figure 3).

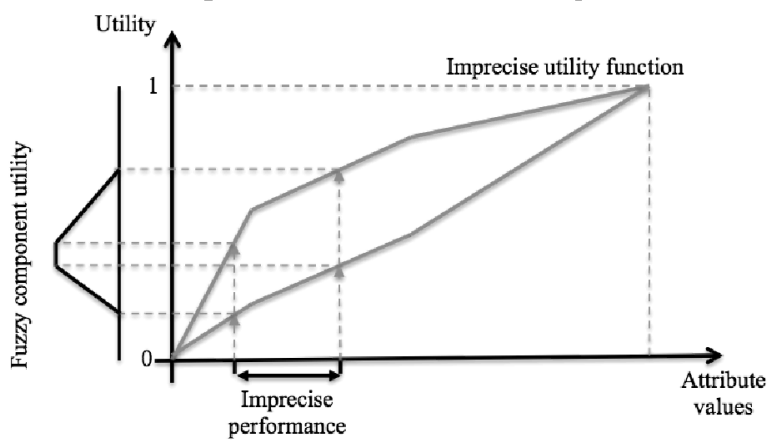

Figure 3. Fuzzy component utilities.

Weights representing the relative importance of criteria in the objective hierarchy have also to be elicited. We use a fuzzy adaptation of the procedure included in the GMAA system for eliciting weights based on tradeoffs (Keeney \& Raiffa, 1976; Jiménez et al., 2006). In this procedure, the elicited individual has to make indifference judgments between lotteries and multiple sure amounts, permitting value intervals as responses. Weight intervals (rectangular fuzzy numbers) or a fuzzy linguistic scale can also be used for direct assignment.

Once the relative importance of the objectives has been rated along the branches of the hierarchy (Figure 2), the attribute weight can be assessed by multiplying the respective weights (represented by trapezoidal fuzzy numbers) of the objectives in the path from the root (global objective) to each leaf (attribute).

\subsection{Fuzzy evaluation of remediation alternatives}

Once the preferences have been quantified, remediation alternatives (including the no action alternative) can be evaluated by means of an additive multi-attribute utility function. The form of the function is $\oplus_{i=1}^{n} \widetilde{w}_{i} \otimes u_{i}\left(\widetilde{x}_{i}\right)$, where $\widetilde{w}_{i}$ is the trapezoidal fuzzy number representing the $i$ th attribute weight, $\tilde{x}_{i}$ is the trapezoidal fuzzy number representing the performance for the remediation alternative in the $i$ th attribute and $u_{i}\left(\widetilde{x}_{i}\right)$ is the fuzzy component utility associated with the above fuzzy performance. We use the $\oplus$ and $\square$ operators proposed in Xu et al. (2010). If the linguistic scale is used to value remediation alternatives in respect of a particular attribute, then the respective trapezoidal fuzzy numbers (see Table 1 and Figure 1) are used as fuzzy component utilities.

Remediation alternatives are then ranked on the basis of the trapezoidal fuzzy numbers representing their overall utility. Methods for ranking fuzzy numbers are divided into four major classes according to Chen \& Hwang (1992). In this case, we intend to use a method based on a similarity function (Vicente et al., 2013) in which the similarity of the fuzzy overall utility of 
each remediation alternative is computed with respect to both the ideal $(1,1,1,1)$ and anti-ideal point $(0,0,0,0)$. The best-ranked alternative will be the most similar to the ideal point and the least similar to the anti-ideal point.

\section{CONCLUSIONS}

The evaluation of remediation alternatives in the Zapadnoe uranium mill tailings site is a complex decision-making problem involving environmental, social and economic criteria. The MCDA methodology provides a framework for structuring the problem incorporating individual or group preferences. Moreover, thanks to fuzzy logic, the inputs to the decision-aiding process may contain vague or imprecise information, which is less demanding for experts and makes the analysis suitable for group decision-making. We have set out a basis for such an evaluation. The actual evaluation is ongoing and will be described in a subsequent publication.

\section{ACKNOWLEDGMENTS}

This paper was supported by the Madrid Regional Government project S-0505/TIC/0230, the Spanish Ministry of Science and Innovation project MTM2011-28983-C03-03 and the Swedish International Development Cooperation Agency (SIDA). The views herein shall not necessarily be taken to reflect the official opinion of SIDA. Thanks are due to Dr. Mike Thorne for useful comments.

\section{REFERENCES}

Belton, V. 1990. Multiple criteria decision analysis - practically the only way to choose. In L.C. Hendry and R.W. Englese (eds.), Operational Research Tutorial Papers 53-101, Birmingham: Operational Research Society.

Brinkhoff, P. 2011. Multi-criteria Analysis for Assessing Sustainability of Remedial Actions. Applications in Contaminated Land Development. Goteborg: Chalmers Univ. of Technology.

Bugay, D. Voitsekhovitch, O., Lavrova, A., Skalskyy, A. \& Tkachenko, E. 2012. Definition of the assessment context and scenarios for the selected cases. Data analyses and data collection. Case A $-\mathrm{Za}-$ padnoe tailings. Report on the Project Ensure-II: Work Package 2, Kiev: Ecomonitor.

Chen, S.J. \& Hwang, C.L. 1992. Fuzzy Multiple Attribute Decision Making: Methods and Applications. New York: Springer.

Dursun, M. 2007. Evaluating solid waste management scenarios using fuzzy multi-criteria decision making approaches. Thesis of Master of Science. Galatasaray University, Turkey.

Goldammer, W., Nüsser, A., Bütow, E. \& Lühr, H.-P. 1999. Integrated assessment of radiological and non-radiological risks at contaminated sites. Mathematische Geologie 3: 53-72.

Keeney, R.L. \& Raiffa H. 1976. Decisions with Multiple Objectives: Preferences and Value-Tradeoffs. New York: Wiley.

Jiménez, A., Ríos-Insua, S. \& Mateos, A. 2006. A generic multi-attribute analysis system. Computers \& Operations Research 33: 1081-1101.

STC-USR \& DIIT. 2000. Progress report on comprehensive investigation of tailings to solve the problem of radioactive waste immobilization and isolation on sites of Dnieprodzerginsk Town. Stage 2. Physical, chemical, spectroscopic and radiospectrum analysis of radioactive waste. Kiev: STC "Cvetnie Metally" and Ukrainian Scientific Research and Design Institute for Industrial Technology.

UHMI. 2009. Analytical measurements of samples of material from tailings according to parameters of spectrum of priority alpha- and gamma-emitting radionuclides of U - Th series using methods of lowbackground semiconductor alpha- and gamma-spectroscopy. Final report on contract No.31 with SE Baryer, Kiev: UHMI Institute (in Ukrainian).

Vicente, E., Mateos, A. \& Jiménez, A. 2013. A new similarity function for generalized trapezoidal fuzzy numbers. Lecture Notes in Computer Science (to appear).

$\mathrm{Xu}$, Z., Shang, S., Qian, W. \& Shu, W. 2010. A method for fuzzy risk analysis based on the new similarity of trapezoidal fuzzy numbers. Expert Systems with Applications 37: 1920-1927.

Zadeh, L.A. 1965. Fuzzy sets. Information and Control 8: 338-353. 